\title{
Waterflooding Huff-n-puff in Tight Oil Cores Using Online Nuclear Magnetic Resonance
}

\author{
Ting Chen ${ }^{1,2,3, *(\mathbb{D})}$, Zhengming Yang ${ }^{2,3}$, Yunhong Ding ${ }^{2,3}$, Yutian Luo ${ }^{1,2,3}$, Dan $\mathrm{Qi}^{1,2,3}$, \\ Wei Lin ${ }^{1,2,3}$ and Xinli Zhao 1,2,3 \\ 1 School of Engineering Sciences, University of Chinese Academy of Sciences, Beijing 100049, China; \\ luoyutian@petrochina.com.cn (Y.L.); qidan69@petrochina.com.cn (D.Q.); linwei15@mails.ucas.edu.cn (W.L.); \\ zhaoxinli17@mails.ucas.edu.cn (X.Z.) \\ 2 Institute of Porous Flow and Fluid Mechanics, Chinese Academy of Sciences, Langfang 065007, China; \\ yzhm69@petrochina.com.cn (Z.Y.); dyhong@petrochina.com.cn (Y.D.) \\ 3 PetroChina Research Institute of Petroleum Exploration \& Development, Beijing 100083, China \\ * Correspondence: chenting15@mails.ucas.edu.cn; Tel.: +86-010-8359-6796
}

Received: 10 May 2018; Accepted: 7 June 2018; Published: 12 June 2018

\begin{abstract}
Given the difficulty in developing waterflooding in tight oil reservoirs, using waterflooding huff-n-puff is an effective method to improve oil recovery. Online nuclear magnetic resonance (NMR) can detect the change in internal oil and water during the core displacement process, and magnetic resonance imaging (MRI) in real time. To improve the tight oil reservoir development effectiveness, cores with different permeability were selected for a waterflooding huff-n-puff experiment. Combined with online NMR equipment, the fluid saturation, recovery rate, and residual oil distribution were studied. The experiments showed that, for tight oil cores, more than $80 \%$ of the pores were sub-micro- and micro-nanopores. More than $77.8 \%$ of crude oil existed in the sub-micro- and micropores, and movable fluids mainly existed in the micropores with a radius larger than $1 \mu \mathrm{m}$. The NMR data and the MRI images both demonstrated that the recovery ratio of waterflooding after waterflooding huff-n-puff was higher than that of conventional waterflooding, and, therefore, residual oil was lower. Choosing two cycles' of waterflooding, huff-n-puff was more suitable for tight oil reservoir development. The production of crude oil increased by $22.2 \%$ in the field pilot test, which preliminarily proved that waterflooding huff-n-puff was suitable for tight oil reservoirs.
\end{abstract}

Keywords: online NMR; tight oil cores; waterflooding huff-n-puff; waterflooding; oil recovery mechanism

\section{Introduction}

With the increasing demand for oil, tight oil reservoirs have gradually become an important field in oilfield exploration and development, given their future potential [1-4]. Because of the very low permeability and non-Darcy flow in tight oil reservoirs [5-7], a starting pressure gradient exists during waterflooding development, which leads to difficulties during injection, a rapid production decline [8-10], and insufficient formation energy challenges [11]. The development of tight oil reservoirs has mainly focused on the combination of horizontal wells and volume fracturing [12-14]. A large number of cracks occurs after reservoir volume fracturing [15-18], and waterflood development often results in a rapid outlet of water from the oil wells [19]. Therefore, the current volume transformation is mainly based on natural energy development [20]. The initial oil production using this process is high, but it decreases rapidly, which leads to low accumulative oil production and poor economic performance [21]. Therefore, studying economically feasible methods of supplementary formation energy for tight oil reservoirs is urgently necessary. 
The tight oil reserves in the Changqing oil field have been proven to be 1 billion tons. Compared with the North American marine tight oil, the tight oil of the Yanchang Formation in the Ordos Basin is mainly composed of lacustrine sediments, with small single sand bodies, thin effective thickness, natural fracture development, low rock brittleness, and a low-pressure coefficient $[11,22,23]$. Therefore, exploration and development are difficult. A tight oil pilot test was performed in the Changqing Oilfield in 2010. In the early stage, according to the advanced low-permeability low-pressure reservoir water injection development model, the cluster well rectangle and diamond reverse nine-point well pattern were used for advanced waterflooding development. The average oil production of a single well in the first year was $1.0 \mathrm{t} /$ day and, in the second year, decreased to $0.47 \mathrm{t} /$ day. The annual rate of decline was $53 \%$. The water content increased from 35.3 to $53.5 \%$ within one year, and the ratio of waterflooded wells was $37.8 \%$ in the first year, with a poor effect of waterflooding. In 2012, a horizontal well volume fracturing test was performed. The average initial production of waterflooding in a five-point well network was $12.1 \mathrm{t} /$ day. The initial production at the seven points of the interlaced well network was $9.2 \mathrm{t} /$ day, which was about 10 times the output of the single well in the vertical well. However, after a half-yearly production, the horizontal wells with a waterflooding development pattern were partially flooded. In 2013, the development test scale of the tight oil horizontal wells was further expanded. The complex fracture network system, composed of artificial fractures and natural fractures of reservoirs, increased the contact volume between the fractures and the reservoir matrix and increased the output of the single well. The retention fluid played a role in supplementing the formation energy, and the pressure coefficient was close to one. At this time, no waterflooding was needed to replenish the energy, and quasi-natural energy exhaustion development was adopted at the initial stage of the horizontal well volume fracturing. In 2014, the tight oil of Changqing Oilfield entered the scale development stage, which mainly used quasi-natural energy development in the horizontal wells. The average daily yield of oil was $10.0 \mathrm{t} /$ day, and the water content was $39.1 \%$. After half a year, the well oil production was $4.9 \mathrm{t} /$ day, and the water content was $44.7 \%$. After one year's production, the formation energy was obviously insufficient, the production capacity declined to $35.5 \%$, and the recovery rate was low (7-8\%). Therefore, supplementary energy methods are urgently needed in the late development of quasi-natural energy exhaustion. Further exploring the rational development mode of tight oil under volume fracturing is also required to efficiently develop tight oil.

From the beginning of the 1960s, researchers have studied potential applications of the huff-n-puff process [24-27], which mainly focused on the field application for carbonate rock and sandstone reservoirs, and carbon dioxide $\left(\mathrm{CO}_{2}\right)$ was mainly used as the injection medium [28-31]. Although the recovery rate of $\mathrm{CO}_{2}$ injection was higher, the cost was much higher than that of waterflooding [32]. In the $\mathrm{CO}_{2}$ injection process, the blockage of the oil reservoir and a decrease in the oil production rate occur [33]. In fractured reservoirs, $\mathrm{CO}_{2}$ may directly flow from injectors to producers through fractures without sweeping through the matrix, thereby reducing the sweep efficiency [34]. Given the problems arising in the development of tight oil reservoirs, waterflooding huff-n-puff has received renewed attention because of its economy and effectiveness [20]. Waterflooding huff-n-puff is suitable for well groups with low production and low formation energy. The depletion development in the early stage of tight oil reservoirs leads to the accumulation of oil at the supply boundary to the oil well under the action of elastic energy or water drive energy. A greater resistance exists around the production well, which leads to reduced production. [35]. In the process of huff-n-puff waterflooding, the formation energy is supplemented by waterflooding, the oil and water are replaced by imbibition, and the replacement crude oil flows into the bottom of the well under differential pressure. The period of waterflooding huff-n-puff is similar to $\mathrm{CO}_{2}$ huff-n-puff, which is divided into three stages: water injection, soak, and oil recovery $[30,31,36]$.

Micro-cracks develop in tight oil reservoirs, and artificial crack networks form during volume fracturing, so tight oil reservoirs are generally regarded as a dual-pore system. The system is composed of two different mediums: a matrix and a fracture. The matrix is characterized by high porosity and low permeability, and the fracture has high permeability and low porosity [37]. This combination 
means that oil and gas are mainly stored in the matrix, and cracks provide the main channel for fluid flow. The oil field development process involves crude oil extraction from the matrix. Because of the imbibition replacement between the matrix and the crack, the fluid flow in the tight oil reservoir is different than that of a traditional reservoir [19]. Imbibition is a complex physical and chemical phenomenon. It is a process where the wetting phase enters the porous medium spontaneously and replaces the non-wetting phase through capillary force action [38]. In the process of imbibition, water first contacts the porous medium. Next, water enters the matrix through capillary force and moves along the wall of the porous medium, replacing part of the immovable oil. Imbibition oil recovery has become an important method used to improve oil production in tight oil reservoirs [39]. The effectiveness of the imbibition process depends on several parameters, including the size of the matrix block, the porosity and permeability of the rock, the viscosity of the fluid, the interfacial tension, the wettability of the rock, and the contact area between the wetting fluid and the matrix. A tight oil reservoir rich in micro-cracks is beneficial to imbibition oil recovery because natural fractures considerably increase the contact area of the fluid and the matrix [38].

Because of a lower fluid content inside the tight oil core, the experimental results of the common huff-n-puff in cores have large measurement errors that are influenced by the change in the external temperature [5]. During the huff-n-puff process, the distribution of fluid in different pores inside the core cannot be obtained in time. If the core is removed from the core holder for NMR detection, the change in the confining pressure and temperature and the fluid evaporation redistribute the fluid in the core, resulting in a larger measurement error [40]. Online NMR equipment can effectively solve the above problems. Online NMR is a core detection technique combining low-field NMR with displacement equipment. Compared with traditional experiments, online NMR can measure the $T_{2}$ spectrum and scan with magnetic resonance imaging during high-temperature and high-pressure displacement experiments without core removal [41]. This technology effectively avoids the dissipation of oil and gas and the change in rock pores after pressure change, the experimental temperature is constant, and the measured data is closer to the actual situation.

This work was performed to study the effect of waterflooding huff-n-puff on the development of tight oil reservoirs and determine the appropriate huff-n-puff cycles. In this study, online NMR technology was used on tight oil cores to compare the waterflooding huff-n-puff and the conventional waterflooding experiment. The NMR data and MRI images were measured at different stages in the experiment. By analyzing the NMR data, the pore structure, oil saturation, and movable fluid saturation of the cores were obtained, and the effects of waterflooding huff-n-puff on oil recovery and residual oil distribution were studied. Through MRI images, the effect of waterflooding huff-n-puff on the development of tight oil reservoir was analyzed. Finally, the field pilot test also confirmed that waterflooding huff-n-puff is a feasible and economic process for tight oil reservoirs.

\section{Fundamental Theory}

\subsection{Nuclear Magnetic Resonance and Magnetic Resonance Imaging Theory}

The NMR rock sample analyzer has an external static magnetic field on its core. The hydrogen nucleus contained in the fluid of the core generates NMR signals for their own nuclear magnetic moment. The NMR signal intensity is proportional to the number of hydrogen protons contained in the sample tested. This principle is used to test the amount of fluid contained in the pores of a rock. Usually, the core NMR test method is used to measure the transverse relaxation time $T_{2}$, which is the time from the hydrogen proton running out of the equilibrium state laterally until the equilibrium state is restored. The amplitude distribution corresponding to the relaxation time $T_{2}$ reflects the size of the specific surface in the rock pores and the strength of the molecular action on their inner surface $[40,42,43]$. The relaxation time of a hydrogen nucleus in each rock pore can be expressed by the following equation:

$$
\frac{1}{T_{2}}=\rho_{2} \frac{S}{V}
$$


where $T_{2}$ is the fluid transverse relaxation time $(\mathrm{ms}), \rho_{2}$ is relaxation rate $(\mu \mathrm{m} / \mathrm{ms})$, and $S / V$ is the pore specific surface $(1 / \mu \mathrm{m})$.

From Equation (1), as larger pores have corresponding smaller specific surfaces, their $T_{2}$ relaxation time is longer, and vice versa: the smaller the pores, the shorter their relaxation time.

A tight oil sandstone core with a permeability of $1.85 \times 10^{-3} \mu \mathrm{m}^{2}$ was used for the waterflooding huff-n-puff experiment as an example. The NMR $T_{2}$ spectra are shown in Figure 1 after saturation with simulated formation water, kerosene, and three cycles of huff-n-puff experiment and after waterflooding.

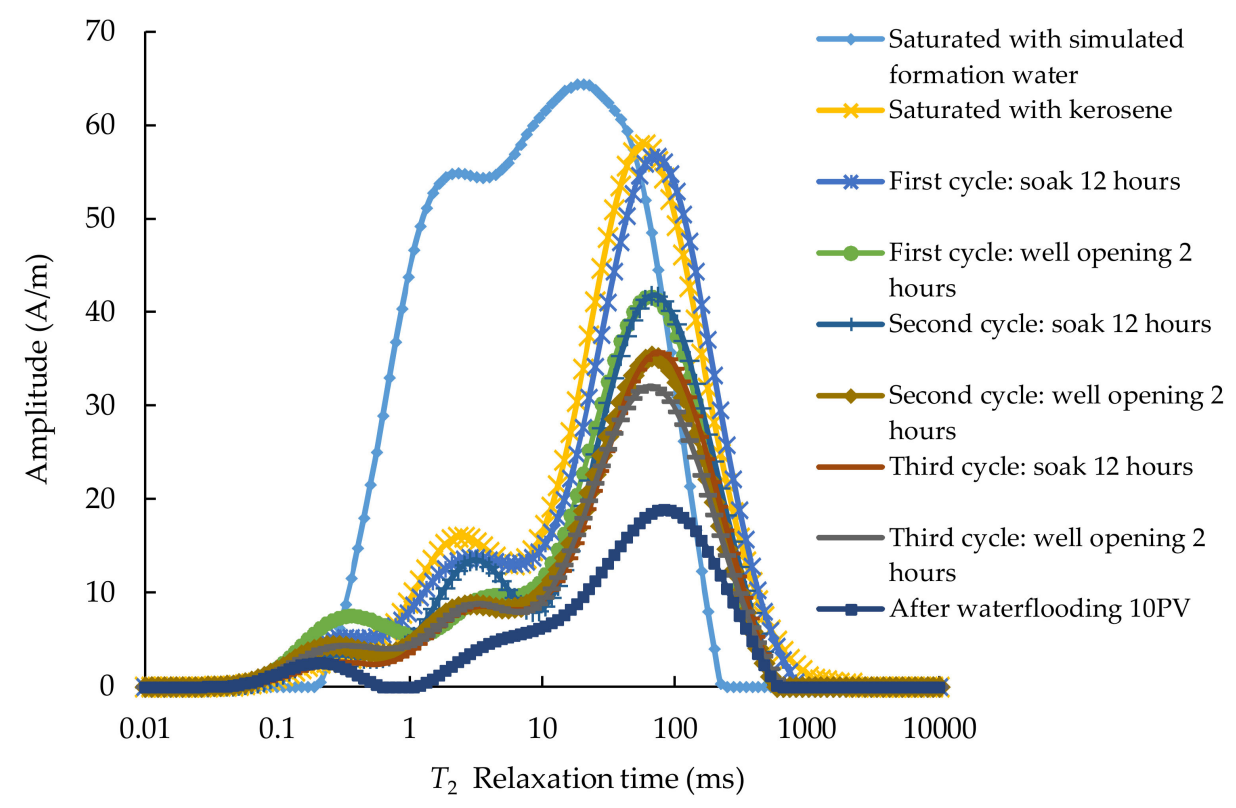

Figure 1. Nuclear magnetic resonance (NMR) $T_{2}$ spectra of a tight oil sandstone core.

MRI was used to image the different layers of the core by processing the reception, space coding, and image reconstruction of the NMR signals. MRI could visualize the change in oil content inside the core during the displacement process.

\subsection{Detection of Various Parameters in the Core by NMR}

NMR testing started with the cores saturated with crude oil. Using the measured NMR data, the initial oil saturation $S_{\mathrm{oi}}$ was calculated as follows:

$$
S_{\mathrm{oi}}=\frac{\sum_{T_{2, \min }}^{T_{2, \max }} A_{\mathrm{i}, \mathrm{o}}}{\sum_{T_{2, \min }}^{T_{2, \max }} A_{\mathrm{i}, \mathrm{w}}} \times 100 \%
$$

where $S_{\mathrm{oi}}$ is the initial oil saturation of the core (\%); $T_{2, \min }$ and $T_{2, \max }$ are the minimum and maximum $T_{2}$ relaxation time, respectively (ms); and $A_{\mathrm{i}, \mathrm{o}}$ and $A_{\mathrm{i}, \mathrm{w}}$ are the corresponding amplitude values of the $T_{2}$ time points on the NMR spectrum curves of saturated oil and saturated water, respectively $(A / m)$.

The computing equation for movable fluid saturation in cores is:

$$
S_{\mathrm{om}}=\frac{\sum_{T_{2, \min }}^{T_{2, \max }} A_{\mathrm{i}, \mathrm{o}}-\sum_{T_{2, \min }}^{T_{2, \max }} A_{\mathrm{i}, \mathrm{a}}}{\sum_{T_{2, \min }}^{T_{2, \max }} A_{\mathrm{i}, \mathrm{w}}} \times 100 \%
$$

where $S_{\text {om }}$ is the movable fluid saturation in the core (\%) and $A_{\mathrm{i}, \mathrm{a}}$ is the corresponding amplitude value of $T_{2}$ time points on the NMR spectrum curves after flooding $(\mathrm{A} / \mathrm{m})$. 
Using the NMR data measured after flooding, the computing equation for the recovery ratio from the cores is as follows:

$$
E_{\mathrm{R}}=\frac{\sum_{T_{2, \min }}^{T_{2, \max }} A_{\mathrm{i}, \mathrm{o}}-\sum_{T_{2, \min }}^{T_{2, \max }} A_{\mathrm{i}, \mathrm{a}}}{\sum_{T_{2, \text { min }}}^{T_{2, \max }} A_{\mathrm{i}, \mathrm{o}}} \times 100 \%
$$

where $E_{\mathrm{R}}$ is the recovery ratio of the core (\%).

Using the NMR technique, the oil phase micro distribution characteristics, both before and after flooding, can be quantitatively studied [44]. The equation for calculating residual oil saturation in the cores is as follows:

$$
S_{\text {or }}=\frac{\sum_{T_{2, \min }}^{T_{2, \max }} A_{\mathrm{i}, \mathrm{a}}}{\sum_{T_{2, \min }}^{T_{2, \max }} A_{\mathrm{i}, \mathrm{w}}} \times 100 \%
$$

where $S_{\text {or }}$ is the residual oil saturation of the core (\%).

\section{Experimental}

\subsection{Geological Survey and Experimental Samples}

The tight oil reservoirs of a block in Ordos Basin, China, studied in this paper have poorly developed natural fractures. The average permeability was $0.78 \times 10^{-3} \mu \mathrm{m}^{2}$, and the average porosity was $13.2 \%$. The main pore type was residual intergranular pore. The pore structures were mainly small pore throats. The average pore throat radius was around $0.19 \mu \mathrm{m}$, and the main pore throat radius values ranged from 0.35 to $1.03 \mu \mathrm{m}$. The reservoirs had poor throat distribution concentration and uniformity. They had strong heterogeneity and obvious non-Darcy seepage flows.

The experimental cores had an average porosity of $17.36 \%$ and an average air permeability of $1.19 \times 10^{-3} \mu^{2}$. A total of four pieces of core were selected and divided into two groups. The specific physical characteristics of the tight oil core samples used in the experiments are listed in Table 1.

The concentration of the brine for simulated formation water was $80 \mathrm{~g} / \mathrm{L}$. To shield the NMR signals, Deuterium water was chosen as the injection medium, and the concentration of salt in Deuterium water was $80 \mathrm{~g} / \mathrm{L}$. Kerosene was chosen as the saturated oil. At $25^{\circ} \mathrm{C}$, the viscosity of kerosene was $1.67 \mathrm{mPa} \cdot \mathrm{s}$, and the density was $0.8 \mathrm{~g} / \mathrm{cm}^{3}$. Each fluid was filled in an intermediate container with a piston.

\begin{tabular}{|c|c|c|c|c|c|}
\hline No. & $\begin{array}{l}\text { Length } \\
(\mathrm{cm})\end{array}$ & $\begin{array}{l}\text { Diameter } \\
(\mathrm{cm})\end{array}$ & $\begin{array}{l}\text { Permeability } \\
\left(\times 10^{-3} \mu \mathrm{m}^{2}\right)\end{array}$ & $\begin{array}{c}\text { Porosity } \\
(\%)\end{array}$ & Development Regime \\
\hline $\mathrm{A}$ & 5.39 & 2.49 & 0.57 & 17.19 & Waterflooding \\
\hline B & 5.35 & 2.40 & 0.58 & 17.52 & Waterflooding after waterflooding huff-n-puff \\
\hline $\mathrm{C}$ & 5.46 & 2.49 & 1.78 & 17.10 & Waterflooding \\
\hline $\mathrm{D}$ & 5.37 & 2.50 & 1.85 & 17.20 & Waterflooding after waterflooding huff-n-puff \\
\hline
\end{tabular}

Table 1. Characteristics of the tight oil sandstone core samples.

\subsection{Experimental Equipment}

The flow chart of the experimental equipment is shown in Figure 2. Two displacement pumps were used together to pressurize the test fluid. Two intermediate containers were used for kerosene and Deuterium water. A thermostat and a pressurized circulating pump were used to provide the same formation temperature and peripheral pressure for the core holder. An online NMR equipment was used to record the NMR $T_{2}$ data and MRI images of the cores during the experiment. 


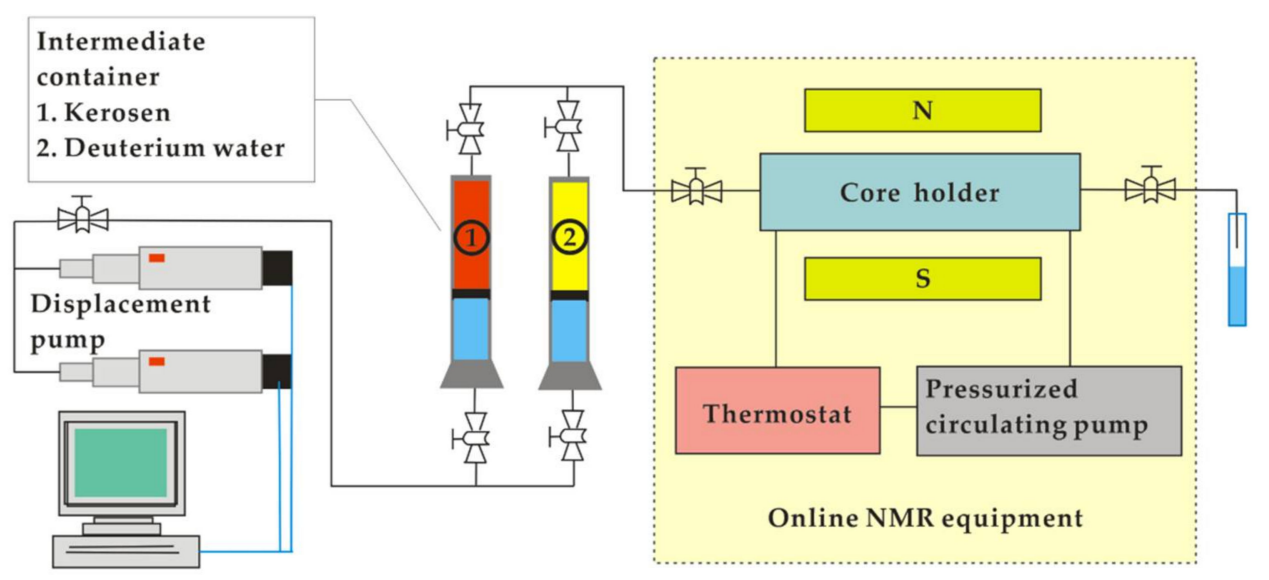

Figure 2. Flow chart of the experimental equipment.

\subsection{Experimental Procedure}

The basic steps of the experiment were as follows. Four pieces of core were selected for labeling, oil washing, and drying, then their dry weight was obtained; the basic parameters were measured, such as diameter, length, air permeability, and porosity. Then, the cores were vacuumed and saturated with simulated formation water. Their NMR $T_{2}$ data and MRI images under saturated water were recorded using the online NMR equipment. The cores were then dried, vacuumed, and saturated with Deuterium water to eliminate the NMR signals of the water phase. A $10 \mathrm{MPa}$ pressure condition was set to saturate each piece of core with kerosenel and the displacement volume was 10 pore volume (PV). After each piece of core was saturated, NMR $T_{2}$ data were recorded using the online NMR equipment. To prevent the introduction of a nuclear magnetic signal, Deuterium water was used to perform waterflooding and the huff-n-puff experiment. Two cores were chosen for the waterflooding experiment. The displacement pressure was $10 \mathrm{MPa}$, and the displacement volume was $10 \mathrm{PV}$. After flooding was completed, NMR $T_{2}$ data and MRI images of the cores were recorded by the online NMR equipment. Other two cores were used for the waterflooding huff-n-puff experiment, for which three cycles were completed at an injection pressure of $10 \mathrm{MPa}$. In each cycle, the soak time was $12 \mathrm{~h}$ with a well opening time of $2 \mathrm{~h}$. After the huff-n-puff experiment, without removing the core, the displacement pressure was set to $10 \mathrm{MPa}$, and the waterflooding experiment was completed at a displacement volume of $10 \mathrm{PV}$. NMR $T_{2}$ data and MRI images of the cores in each cycle and after completing flooding were recorded with the online NMR equipment. The NMR data and MRI images were used to study the core pores, oil saturation, movable fluid saturation, oil displacement effect, and residual oil distribution.

\section{Results and Discussion}

\subsection{NMR Measuring Results of the Core Pores}

The NMR $T_{2}$ distribution of the cores saturated with simulated formation water was converted into pore radius distribution $[43,45,46]$. The NMR data obtained from the cores saturated with simulated formation water were converted into pore radius distribution. The results are shown in Figure 3.

According to three pore radius boundaries [47], i.e., $0.05,0.1$, and $1 \mu \mathrm{m}$, the pores were classified as nanopores, micro-nanopores, sub-micropores, and micropores. The pore radius of the tight oil cores was mainly less than $10 \mu \mathrm{m}$, and more than $80 \%$ were sub-micropores and micro-nanopores. 


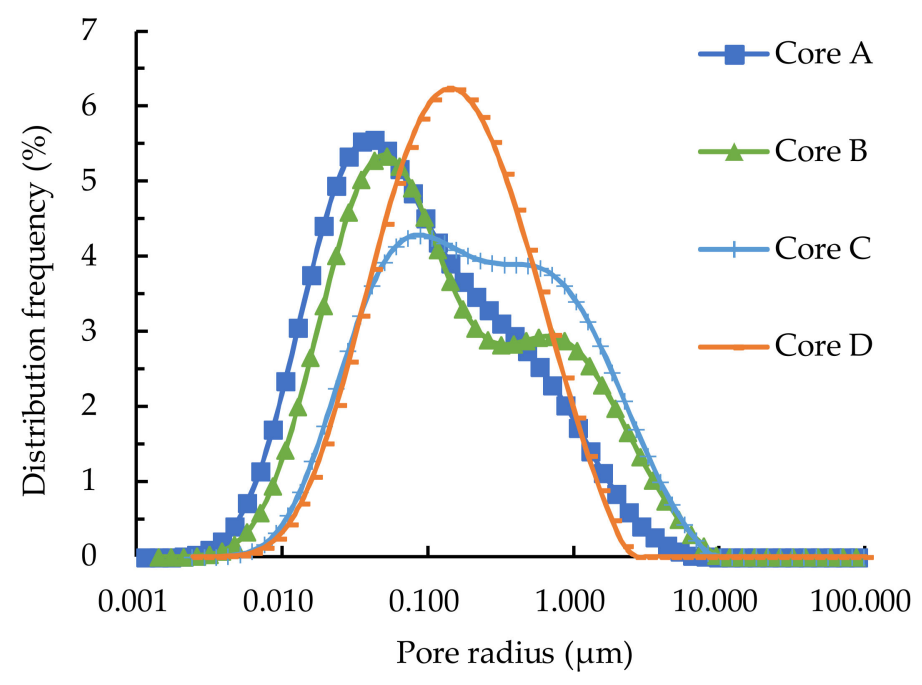

Figure 3. Distribution frequencies of the core pore radius.

\subsection{Study on Oil Saturation and Movable Fluid Saturation}

The method for calculating the ratios of oil saturation in different pores was the same as that used for the ratio of the saturated simulated formation water. Table 2 shows the oil saturation in different pores after the core was saturated with crude oil. More than $77.8 \%$ of crude oil was found in sub-micropores and micropores, and the ratio of crude oil stored in micro-nanopores increased with decreasing permeability. The main reason for this finding is that the total volume of nano- and micro-nanopores was small. Though the total amount of these pores was large, the proportion of stored crude oil was very low. The fluid in the nanopores was considered immovable. Therefore, saturating the nanopores with crude oil was difficult. Overall, the higher the permeability of this batch of cores, the lower the oil saturation. The reason for this anomaly is that many large pores and channels with higher permeability were present inside the cores, creating a small flow resistance. When the cores were penetrated by crude oil, the fine pores could hardly be saturated. As little difference exists inside the cores between large and small pores with lower permeability, under the same displacement pressure, the cores required more time to become saturated at $10 \mathrm{PV}$ and then they could become more fully saturated. In addition to the above reasons, slip flow and diffusion occurred especially at low pressure in the nanopores. The preferential flow path led to significant porosity and permeability underestimation. A practice that can be used to avoid this misinterpretation is to measure several permeability values under different pressures. High-pressure might be more indicative of fluid phase permeability [48-50].

Table 2. Oil saturations for the cores and their different pores saturated with the crude oil.

\begin{tabular}{|c|c|c|c|c|c|c|}
\hline \multirow{2}{*}{ No. } & \multirow{2}{*}{$\begin{array}{l}\text { Permeability } \\
\left(\times 10^{-3} \mu \mathrm{m}^{2}\right)\end{array}$} & \multicolumn{4}{|c|}{ Initial Oil Saturation $\left(S_{o i}\right)$ in Different Pores Share of Total $(\%)$} & \multirow{2}{*}{ Total $S_{\text {oi }}(\%)$} \\
\hline & & Nano & Micro-Nano & Sub-Micro & Micro & \\
\hline A & 0.57 & 1.6 & 9.9 & 25.7 & 16.7 & 53.9 \\
\hline B & 0.58 & 1.9 & 9.2 & 24.7 & 19.8 & 55.6 \\
\hline C & 1.78 & 1.7 & 10.3 & 26.8 & 18.5 & 57.3 \\
\hline $\mathrm{D}$ & 1.85 & 1.8 & 11.7 & 32.3 & 15.2 & 61.0 \\
\hline
\end{tabular}

Figure 4 provides the movable fluid saturations in different pores of each core. Only a small difference was observed between the movable fluid saturations in the various cores. In tight oil cores, hardly any relationship was found between permeability and movable fluid saturation. The amount of movable fluid in the micro-nanopores was not more than $10 \%$. A small amount of movable fluid was found in the sub-micropores. Movable fluids mainly existed in the micropores with a radius larger than $1 \mu \mathrm{m}$. 


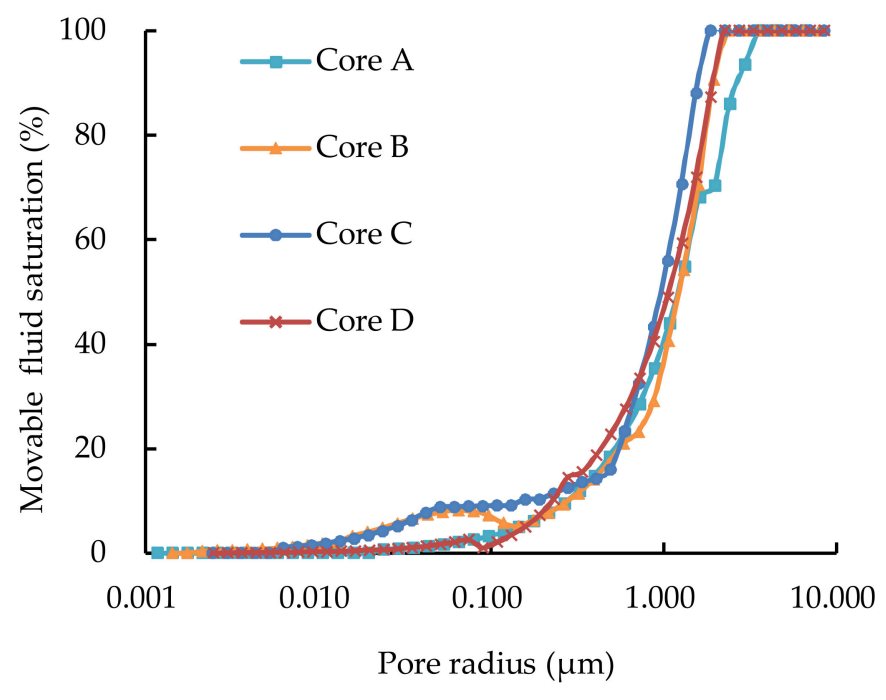

Figure 4. Movable fluid saturations in the different pore cores.

\subsection{Study on Oil Displacement Effect and Residual Oil Distribution}

The recovery ratio of crude oil in each piece of core was calculated, as shown in Figure 5 and Table 3. For tight oil cores, the recovery ratio of waterflooding huff-n-puff was lower than that of conventional waterflooding. A large amount of kerosene was produced during the waterflooding stage after huff-n-puff. The oil in the heart of the rock entered the macropores by imbibition during the waterflooding huff-n-puff process; however, the pressure was insufficient to extract the oil from the core. The subsequent waterflooding provided enough pressure, thus effectively improving the recovery ratio.

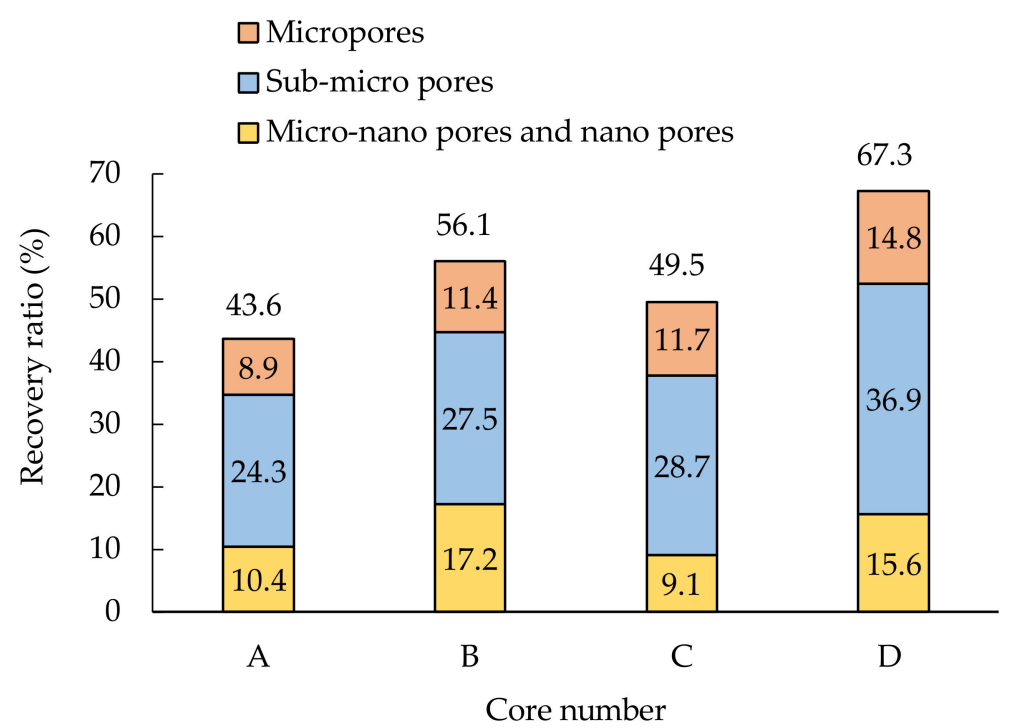

Figure 5. Recovery ratio for the cores and their different pores. 
Table 3. Recovery ratio for the cores and their different pores in the huff-n-puff experiment.

\begin{tabular}{|c|c|c|c|c|c|c|c|}
\hline \multirow[t]{2}{*}{ No. } & \multirow[t]{2}{*}{ Stage } & \multicolumn{4}{|c|}{$\begin{array}{c}\text { Recovery Ratio }\left(E_{\mathrm{R}}\right) \text { in Different Pores Share of } \\
\text { Total }(\%)\end{array}$} & \multirow{2}{*}{$E_{\mathrm{R}}(\%)$} & \multirow{2}{*}{ Total $E_{\mathrm{R}}(\%)$} \\
\hline & & Nano & Micro-Nano & Sub-Micro & Micro & & \\
\hline \multirow{4}{*}{$\mathrm{B}$} & First cycle & 1.8 & 5.5 & 11.2 & 4.7 & 23.2 & \multirow{4}{*}{56.1} \\
\hline & Second cycle & 0.5 & 2.5 & 6.8 & 3.9 & 13.7 & \\
\hline & Third cycle & 0.1 & 0.3 & 1.3 & 0.6 & 2.3 & \\
\hline & Waterflooding & 1.7 & 4.8 & 8.2 & 2.2 & 16.9 & \\
\hline \multirow{4}{*}{$\mathrm{D}$} & First cycle & 0.5 & 3.3 & 15.9 & 7.6 & 27.3 & \multirow{4}{*}{67.3} \\
\hline & Second cycle & 0.3 & 3.0 & 6.0 & 1.9 & 11.2 & \\
\hline & Third cycle & 0.1 & 0.3 & 2.3 & 0.9 & 3.6 & \\
\hline & Waterflooding & 2.6 & 5.5 & 12.7 & 4.4 & 25.2 & \\
\hline
\end{tabular}

The study of the recovery ratio of each cycle showed that the first cycle for the two cores accounted for $41.4 \%$ and $40.6 \%$ of the total recovery ratio, respectively. The second cycle of the two cores accounted for $24.4 \%$ and $16.6 \%$ of the total recovery ratio, respectively, and the third cycle was responsible for $4.1 \%$ and $5.3 \%$ of the total recovery ratio, respectively. Overall, the displacement stage accounted for $30.1 \%$ and $37.4 \%$ of the total recovery ratio. The first two huff-n-puff cycles significantly contributed to the recovery ratio. The contribution of the third huff-n-puff cycle was less, which indicates that the remaining oil was difficult to recover via imbibition. In contrast to the recovery ratios of different pores, the overall recovery ratio increased in every pore type via huff-n-puff. Notably, the recovery ratios of the micropores and sub-micropores were higher than that of conventional waterflooding. The reason for this phenomenon is that most of the pores in the reservoir were hydrophilic. In the process of soaking, molecular diffusion occurs, which is important in tight reservoirs, causing a slight decrease in the average reservoir pressure. During the production period, molecular diffusion can mitigate the reservoir pressure decline. The hydrophilic nature of the reservoir accelerated the diffusion process of water and water imbibition and displaced oil into the larger pores [51].

The calculation results for the residual oil saturation in the different pores of each core are shown in Figure 6 and Table 4. Comparing the residual oil saturation of the two groups, the residual oil saturation was higher than in conventional waterflooding using only huff-n-puff; however, the residual oil saturation of waterflooding huff-n-puff was obviously lower than that of conventional waterflooding.

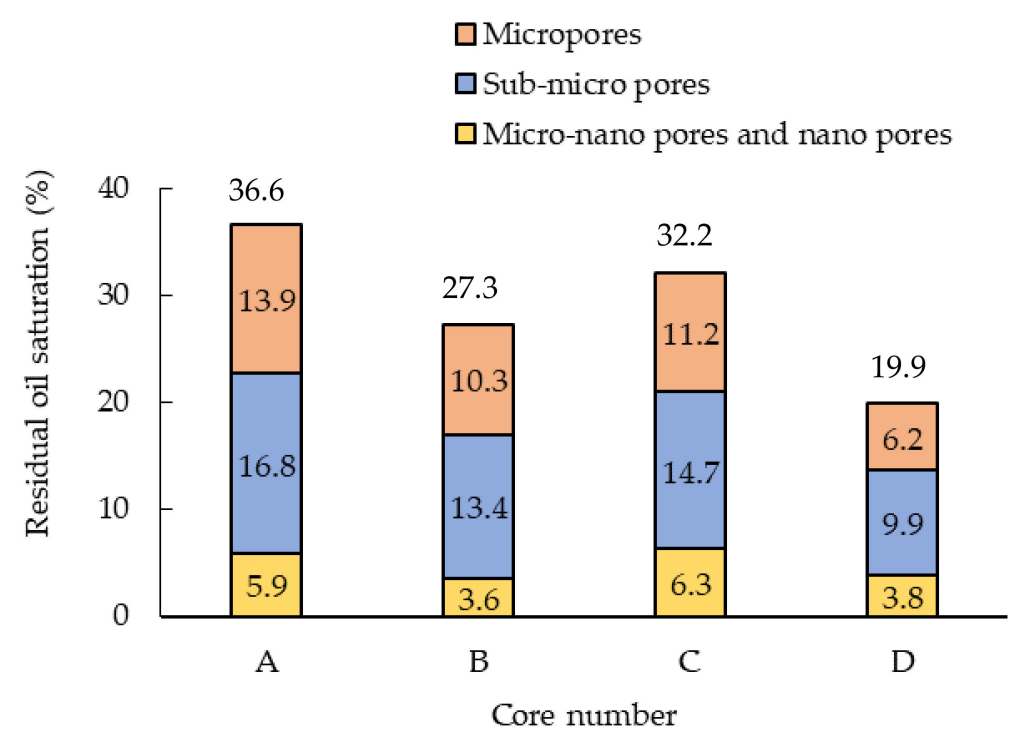

Figure 6. Residual oil saturations for the cores and their different pores. 
Table 4. Residual oil saturations for the cores and their different pores in the huff-n-puff experiment.

\begin{tabular}{ccccccc}
\hline \multirow{2}{*}{ No. } & Stage & \multicolumn{4}{c}{$\begin{array}{c}\text { Residual Oil Saturation }\left(S_{\text {or }}\right) \text { in Different Pores } \\
\text { Share of Total (\%) }\end{array}$} & \multirow{2}{*}{$S_{\text {or }}$ (\%) } \\
\cline { 3 - 6 } & & Nano & Micro-Nano & Sub-Micro & Micro & \\
\hline \multirow{4}{*}{ B } & First cycle & 1.2 & 8.3 & 23.9 & 16.2 & 48.3 \\
& Second cycle & 1.0 & 6.9 & 19.2 & 13.0 & 40.1 \\
& Third cycle & 1.0 & 6.7 & 18.5 & 12.3 & 38.5 \\
& Waterflooding & 0.5 & 3.1 & 13.4 & 10.3 & 27.3 \\
\hline \multirow{4}{*}{ D } & First cycle & 1.3 & 9.9 & 22.6 & 10.5 & 44.3 \\
& Second cycle & 0.9 & 8.2 & 19.0 & 9.4 & 37.5 \\
& Third cycle & 0.9 & 8.0 & 17.6 & 8.9 & 35.4 \\
& Waterflooding & 0.6 & 3.2 & 9.9 & 6.2 & 19.9 \\
\hline
\end{tabular}

Tables $2-4$ and Figures 5 and 6 show that the sub-micropores contributed $49-58 \%$ of the produced oil. Because the soaking process can promote imbibition, replacing the oil from the small pores into the macropores and fractures and then accumulating oil to form the oil belt could replace more oil. Waterflooding after huff-n-puff was less than $25-38 \%$ of conventional waterflooding in residual oil saturation. In the first cycle, waterflood huff-n-puff effectively replaced oil in the micro-nanopores and nanopores. The lower the permeability, the better the effect of soaking on recovery in the small pores, and the greater the proportion of imbibition in oil recovery. Therefore, the lower the permeability, the more obvious the effect of waterflooding huff-n-puff on oil recovery. The effect of the third cycle of huff-n-puff on tight oil reservoir recovery was not obvious, because after the first two cycles, the residual oil was difficult to move via soaking. Therefore, choosing two cycles of waterflooding after waterflooding huff-n-puff is more suitable for tight oil reservoir development, which could significantly improve the oil recovery ratio while being time-efficient.

\subsection{MRI Images of the Cores at Various Stages of the Experiment}

MRI images can help depict the changes in a core during the development process [40]. Only kerosene had nuclear magnetic signals in the heart of the experimental core. The brighter the image, the more oil in the core. Figures 7 and 8 show the MRI images of core A and core B at different stages of the experiment. The imaging direction was in the coronal plane. The remaining oil in core B was significantly less than in core A, compared with the initial saturation oil stage. The end effect existed at the exit side, which showed a high brightness area at the end of the image. The reason for this observation is that the oil gathered under the internal pressure at the exit at the oil recovery stage. When the oil was removed from the core at the displacement stage, the end effect disappeared.

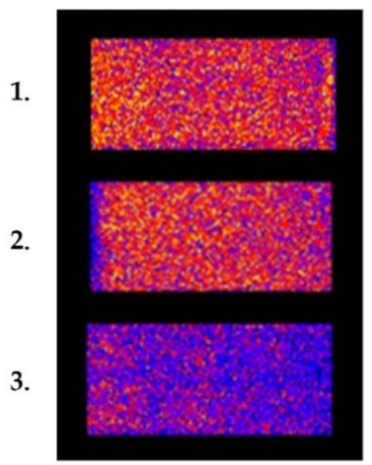

Figure 7. Magnetic resonance imaging (MRI) of Core A: (1) Saturated kerosene state; (2) after displacing 1 pore volume (PV); (3) after displacing $10 \mathrm{PV}$. 


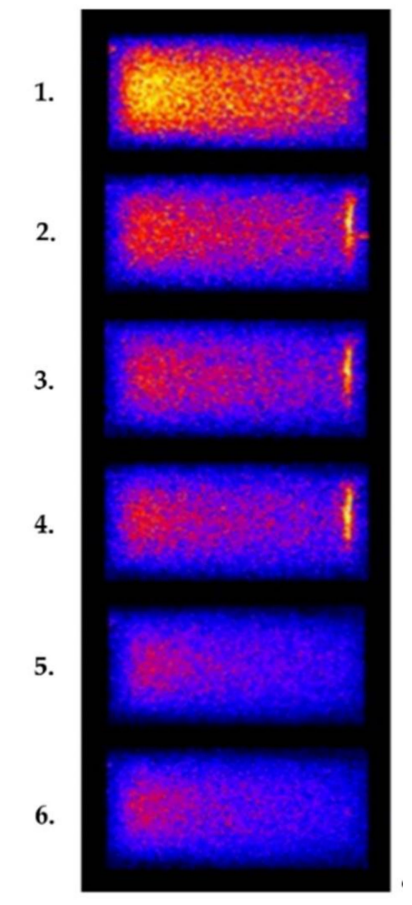

Figure 8. MRI of Core B: (1) Saturated kerosene state; (2) after the first cycle of huff-n-puff; (3) after the second cycle of huff-n-puff; (4) after the third cycle of huff-n-puff; (5) after displacing 1 PV; (6) after displacing $10 \mathrm{PV}$.

\subsection{Field Test}

In 2017, the waterflooding huff-n-puff test of a horizontal well was performed in the tight oil of the Changqing Oilfield. From the production data of four wells developed by waterflooding huff-n-puff in the $\mathrm{X}$ well area, within seven days, the average daily production oil of a single well increased from $9.9 \mathrm{t}$ to $18.2 \mathrm{t}$, and the water content decreased from 50 to $26.7 \%$. After 30 days' production, the daily oil production in a single well was stable at $12.1 \mathrm{t}$, and the water content was stable at $23 \%$. This is because, as a result of the strong conductivity of the volume fracturing in a relatively short time under capillary pressure, the effective imbibition and replacement between the crude oil and the injected water were removed, and the preliminary effect of waterflooding huff-n-puff of tight oil reservoir was achieved.

\section{Conclusions}

Online NMR equipment was used to complete waterflooding huff-n-puff experiments in tight oil cores and to obtain data in the process displacement without core removal. The pore structure of the tight oil cores and the changes in oil saturation in different pores during the huff-n-puff process were compared with those of conventional waterflooding, which provides a theoretical basis for the rational exploitation of tight oil reservoirs.

Some conclusions from the above study can be summarized as follows. The pore radius of the tight oil cores was mainly below $10 \mu \mathrm{m}$, and more than $80 \%$ were sub-micro- and micro-nanopores. More than $77.8 \%$ crude oil existed in sub-micro- and micropores, and the ratio of crude oil stored in the micro-nano pores increased with decreasing permeability. Movable fluids mainly existed in micropores with a radius larger than $1 \mu \mathrm{m}$.

For tight oil cores, the recovery ratio of waterflooding huff-n-puff was lower than in conventional waterflooding, and 16.9-25.2\% kerosene was produced at the waterflooding stage after huff-n-puff. The residual oil saturation of waterflooding huff-n-puff was obviously lower than that of conventional waterflooding. To significantly improve the oil recovery ratio while remaining time-efficient, using two cycles of waterflooding huff-n-puff was more suitable for tight oil reservoir waterflooding development. 
From the MRI images, the residual oil of waterflooding after waterflooding huff-n-puff was less than that of conventional waterflooding.

In the field pilot test, the production of crude oil increased by $22.2 \%$, which preliminarily proved that waterflooding huff-n-puff was suitable for tight oil reservoirs.

Author Contributions: Each author has made contributions to the present paper. Conceptualization, T.C., Z.Y. and Y.D.; Data curation, T.C., Y.L., D.Q., W.L. and X.Z.; Investigation, T.C., Z.Y., Y.D. and Y.L.; Validation, T.C., D.Q. and X.Z.; Writing—review \& editing, T.C. All authors have read and approved the final manuscript.

Acknowledgments: We would like to express appreciation to the following financial support: Major national science and technology special project: Physical simulation method and percolation mechanism of ultra-low permeability reservoir (2017ZX05013-001).

Conflicts of Interest: The authors declare no conflict of interest.

\section{References}

1. Velasco, R.; Panja, P.; Pathak, M. Analysis of North-American Tight Oil Production. AIChE J. 2018, 64, $1479-1484$. [CrossRef]

2. Jia, C.; Zheng, M.; Zhang, Y. Unconventional hydrocarbon resources in China and the prospect of exploration and development. Pet. Explor. Dev. 2012, 49, 43-44. [CrossRef]

3. Zou, C.; Tao, S.; Yang, Z.; Hou, L.; Yuan, X.; Zhu, R.; Jia, J.; Wu, S.; Gong, Y.; Gao, X.; et al. Development of Petroleum Geology in China: Discussion on Continuous Petroleum Accumulation. J. Earth Sci. 2013, 24, 796-803. [CrossRef]

4. Zou, C.; Zhai, G.; Zhang, G.; Wang, H.; Zhang, G.; Li, J.; Wang, Z.; Wen, Z.; Ma, F.; Liang, Y.; et al. Formation, distribution, potential and prediction of global conventional and unconventional hydrocarbon resources. Pet. Explor. Dev. 2015, 42, 13-25. [CrossRef]

5. Zeng, J.; Cheng, S.; Kong, X.; Guo, K.; Wang, H. Non-Darcy flow in oil accumulation (oil displacing water) and relative permeability and oil saturation characteristics of low-permeability sandstones. Pet. Sci. 2010, 7, 20-30. [CrossRef]

6. Yao, D.; Ge, J. Characteristics of non-Darcy flow in low-permeability reservoirs. Pet. Sci. 2011, 8, 55-62. [CrossRef]

7. Hadi, S.J.; Peyman, P. Significance of non-Darcy flow effect in fractured tight reservoirs. J. Nat. Gas. Sci. Eng. 2015, 24, 132-143. [CrossRef]

8. Sun, S.; Shu, L.; Zeng, Y.; Cao, J.; Feng, Z. Porosity-permeability and textural heterogeneity of reservoir sandstones from the Lower Cretaceous Putaohua Member of Yaojia Formation, Weixing Oilfield, Songliao Basin, Northeast China. Mar. Pet. Geol. 2007, 24, 109-127. [CrossRef]

9. Zou, C.; Zhu, Ru.; Liu, K.; Su, L.; Bai, B.; Zhang, X.; Yuan, X.; Wang, J. Tight gas sandstone reservoirs in China: Characteristics and recognition criteria. J. Pet. Sci. Eng. 2012, 88-89, 82-91. [CrossRef]

10. Zhao, J.; Bai, Y.; Qing, C.; Chuang, E. Quasi-continuous hydrocarbon accumulation: A new pattern for large tight sand oilfields in the ordos basin. Oil Gas Geol. 2012, 33, 811-827. [CrossRef]

11. Lai, J.; Wang, G.; Ran, Y.; Zhou, Z.; Cui, Y. Impact of diagenesis on the reservoir quality of tight oil sandstones: The case of Upper Triassic Yanchang Formation Chang 7 oil layers in Ordos Basin, China. J. Pet. Sci. Eng. 2018, 145, 54-65. [CrossRef]

12. Ghanbari, E.; Dehghanpour, H. The fate of fracturing water: A field and simulation study. Fuel 2016, 163, $282-294$. [CrossRef]

13. Wang, H.; Liao, X.; Zhao, X. Study of tight oil reservoir flow regimes in different treated horizontal well. J. Energy Inst. 2015, 88, 198-204. [CrossRef]

14. Ozkan, E.; Brown, M.; Raghavan, R.; Kazeml, H. Comparison of Fractured-Horizontal-Well Performance in Tight Sand and Shale Reservoirs. SPE Reserv. Eval. Eng. 2011, 14, 248-259. [CrossRef]

15. Fan, D.; Yao, J.; Sun, H.; Zeng, H.; Wang, W. A composite model of hydraulic fractured horizontal well with stimulated reservoir volume in tight oil \& gas reservoir. AAPG Bull. 2015, 24, 115-123. [CrossRef]

16. Zhao, Y.; Zhang, L.; Luo, J.; Zhang, B. Performance of fractured horizontal well with stimulated reservoir volume in unconventional gas reservoir. J. Hydrol. 2014, 512, 447-456. [CrossRef]

17. Wang, H.; Liao, N.; Lu, N.; Cai, Z.; Liao, C.; Dou, X. A study on development effect of horizontal well with SRV in unconventional tight oil reservoir. J. Energy Inst. 2014, 87, 114-120. [CrossRef] 
18. Guo, C.; Xu, J.; Wei, M.; Jiang, R. Experimental study and numerical simulation of hydraulic fracturing tight sandstone reservoirs. Fuel 2015, 159, 334-344. [CrossRef]

19. Xie, J.; Zhu, Z.; Hu, R.; Liu, J. A calculation method of optimal water injection pressures in natural fractured reservoirs. J. Pet. Sci. Eng. 2015, 133, 705-712. [CrossRef]

20. Li, Z.; Qu, X.; Liu, W.; Lei, Q.; Sun, H.; He, Y. Development modes of Triassic Yanchang Formation Chang 7 Member tight oil in Ordos Basin, NW China. Pet. Explor. Dev. 2015, 42, 241-246. [CrossRef]

21. Zhao, J.; Fan, J.; He, Y.; Yang, Z.; Wei, G.; Gao, W. Optimization of horizontal well injection-production parameters for ultra-low permeable-tight oil production: A case from Changqing Oilfield, Ordos Basin. Pet. Explor. Dev. 2015, 42, 74-82. [CrossRef]

22. Li, P.; Zheng, M.; Bi, H.; Wu, S.; Wang, X. Pore throat structure and fractal characteristics of tight oil sandstone: A case study in the Ordos Basin, China. J. Pet. Sci. Eng. 2017, 149, 665-674. [CrossRef]

23. Wang, Y.; Liu, L.; Li, S.; Ji, H.; Xu, Z.; Luo, Z.; Xu, T.; Li, L. The forming mechanism and process of tight oil sand reservoirs: A case study of Chang 8 oil layers of the Upper Triassic Yanchang Formation in the western Jiyuan area of the Ordos Basin, China. J. Pet. Sci. Eng. 2017, 158, 29-46. [CrossRef]

24. Combs, G.D.; Knezek, R.B. Gas injected for upstructure drainage. In Proceedings of the SPE 44th Annual Fall Meeting, Denver, CO, USA, 28 September-1 October 1969.

25. Haskin, H.K.; Alston, R.B. An Evaluation of $\mathrm{CO}_{2}$ Huff ' $n$ ' Puff Tests in Texas. In Proceedings of the 61st Annual Technical Conference and Exhibition of the Society of Petroleum Engineers, New Orleans, LA, USA, 5-8 October 1986.

26. Wehner, S.C.; Prieditis, J. $\mathrm{CO}_{2}$ Huff-n-Puff: Initial Results form a Waterflooded SSC Reservoir. In Proceedings of the Permian Basin Oil \& Gas Recovery Conference, Midland, TX, USA, 27-29 March 1996.

27. Zhang, Y.P.; Sayegh, S.G.; Huang, S. Laboratory Investigation of Enhanced Light-Oil Recovery by $\mathrm{CO}_{2} /$ Flue Gas Huff-n-Puff Process. In Proceedings of the Petroleum Society's 5th Canadian International Petroleum Conference (55th Annual Technical Meeting), Calgary, AB, Canada, 8-10 June 2004.

28. Asghari, K.; Torabi, F. Laboratory Experimental Results of Huff ' $n$ ' Puff $\mathrm{CO}_{2}$ Flooding in a Fractured Core System. In Proceedings of the SPE Annual Technical Conference and Exhibition, Anaheim, CA, USA, 11-14 November 2007.

29. Song, C.; Yang, D. Performance Evaluation of $\mathrm{CO}_{2}$ Huff-n-puff Processes in Tight Oil Formations. In Proceedings of the SPE Unconventional Resources Conference-Canada, Calgary, AB, Canada, 5-7 November 2013.

30. Ma, J.; Wang, X.; Gao, R.; Zeng, F.; Huang, C.; Tontiwachwuthikul, P.; Liang, Z. Enhanced light oil recovery from tight formations through $\mathrm{CO}_{2}$ huff ' $\mathrm{n}$ ' puff processes. Fuel 2015, 154, 35-44. [CrossRef]

31. Pu, W.; Wei, B.; Jin, F.; Li, Y.; Jia, H.; Liu, P.; Tang, Z. Experimental investigation of $\mathrm{CO}_{2}$ huff-n-puff process for enhancing oil recovery in tight reservoirs. Chem. Eng. Res. Des. 2016, 111, 269-276. [CrossRef]

32. Burton, M.; Bryant, SL. Eliminating Buoyant Migration of Sequestered $\mathrm{CO}_{2}$ Through Surface Dissolution: Implementation Costs and Technical Challenges. SPE Reserv. Eval. Eng. 2009, 12, 399-407. [CrossRef]

33. Zhou, T.; Liu, X.; Yang, Z.; Li, X.; Wang, S. Experimental analysis on reservoir blockage mechanism for $\mathrm{CO}_{2}$ flooding. Pet. Explor. Dev. 2015, 42, 548-553. [CrossRef]

34. Jin, L.; Sorensen, J.A. Improving Oil Recovery by Use of Carbon Dioxide in the Bakken Unconventional System: A Laboratory Investigation. SPE Reserv. Eval. Eng. 2017, 20, 602-612. [CrossRef]

35. Wei, B.; Lu, L.; Pu, W.; Wu, R.; Zhang, X.; Li, Y.; Jin, F. Production dynamics of $\mathrm{CO}_{2}$ cyclic injection and $\mathrm{CO}_{2}$ sequestration in tight porous media of Lucaogou formation in Jimsar sag. J. Pet. Sci. Eng. 2017, 157, 1071-1081. [CrossRef]

36. Yu, W.; Lashgari, H.; Sepehrnoori, K. Simulation Study of $\mathrm{CO}_{2}$ Huff-n-Puff Process in Bakken Tight Oil Reservoirs. In Proceedings of the SPE Western North American and Rocky Mountain Joint Regional Meeting, Denver, CO, USA, 16-18 April 2014.

37. Zhang, Z.; Shi, Y.; Li, H.; Jin, W. Experimental study on the pore structure characteristics of tight sandstone reservoirs in Upper Triassic Ordos Basin China. Energy Explor. Exploit. 2016, 34, 418-439. [CrossRef]

38. Gu, X.; Pu, C.; Huang, H.; Huang, F.; Li, Y.; Liu, C.; Liu, H. Micro-influencing mechanism of permeability on spontaneous imbibition recovery for tight sandstone reservoirs. Pet. Explor. Dev. 2017, 44, 948-954. [CrossRef]

39. Wang, J.; Liu, Y.; Chen, M.; Liu, L.; Gao, J. Experimental study on dynamic imbibition mechanism of low permeability reservoirs. Pet. Explor. Dev. 2009, 36, 86-90. [CrossRef]

40. Li, S.; Tang, J.; Ding, Y.; Liu, S.; Liu, G.; Cai, B. Recovery of Low Permeability Reservoirs Considering Well Shut-Ins and Surfactant Additivities. Energies 2017, 10. [CrossRef] 
41. Di, Q.; Zhang, J.; Hua, S.; Chen, H.; Gu, C. Visualization experiments on polymer-weak gel profile control and displacement by NMR technique. Pet. Explor. Dev. 2017, 44, 294-298. [CrossRef]

42. Zhang, P.; Lu, S.; Li, J.; Chen, C.; Xue, H.; Zhang, J. Petrophysical characterization of oil-bearing shales by low-field nuclear magnetic resonance (NMR). Mar. Pet. Geol. 2018, 89, 775-785. [CrossRef]

43. Lyu, C.; Ning, Z.; Wang, Q.; Chen, M. Application of NMR T-2 to Pore Size Distribution and Movable Fluid Distribution in Tight Sandstones. Energy Fuels 2018, 32, 1395-1405. [CrossRef]

44. Wang, X.; Yang, Z.; Li, H.; Guo, H. Microscopic Distribution of Remaining Oil of Ultra-low Permeability Reservoir by using NMR Technique. J. Basic Sci. Eng. 2013, 21, 702-709. [CrossRef]

45. Wang, X.; Yang, Z. Experimental study on pore structure of low permeability core with NMR spectra. J. Southwest Pet. Univ. (Sci. Tech. Ed.) 2010, 32, 69-72. [CrossRef]

46. Guo, H.; Zhu, Q.; Meng, Z.; Li, H. Research on the Moveable Oil in Tight Oil Reservoir with NMR and Centrifugal Experiment. Appl. Mech. Mater. 2014, 641-642, 434-440. [CrossRef]

47. Chen, T.; Yang, Z.; Wang, X.; Xiao, P.; Wang, X.; Ma, Z. Oil displacement mechanism for the active water flooding in tight oil reservoirs. Pet. Geol. Oilfield Dev. Daqing 2017, 36, 169-174. [CrossRef]

48. Jia, B.; Tsau, J.S.; Barati, R. Evaluation of Core Heterogeneity Effect on Pulse-decay Experiment. In Proceedings of the 31st International Symposium of the Society of Core Analysts, Vienna, Austria, 28 August-1 September 2017.

49. Jia, B.; Tsau, J.S.; Barati, R. A Workflow to Estimate Shale Gas Permeability Variations during the Production Process. Fuel 2018, 220, 879-889. [CrossRef]

50. Jia, B.; Tsau, J.S.; Barati, R. Different Flow Behaviors of Low-pressure and High-pressure $\mathrm{CO}_{2}$ in Shales. In Proceedings of the SPE/AAPG/SEG Unconventional Resources Technology Conference, Austin, TX, USA, 24-26 July 2017. [CrossRef]

51. Jia, B.; Tsau, J.S.; Barati, R. Role of molecular diffusion in heterogeneous, naturally fractured shale reservoirs during $\mathrm{CO}_{2}$ huff-n-puff. J. Pet. Sci. Eng. 2018, 164, 31-42. [CrossRef]

(C) 2018 by the authors. Licensee MDPI, Basel, Switzerland. This article is an open access article distributed under the terms and conditions of the Creative Commons Attribution (CC BY) license (http:/ / creativecommons.org/licenses/by/4.0/). 